\title{
복 Fermilab
}

\section{Directoromite}

\section{MEMORANDUM OF UNDERSTANDING FOR THE 2011 - 2012 NEUTRINO PROGRAM}

\section{T-1020}

NaI Crystal Test for DM-Ice

November 3, 2011

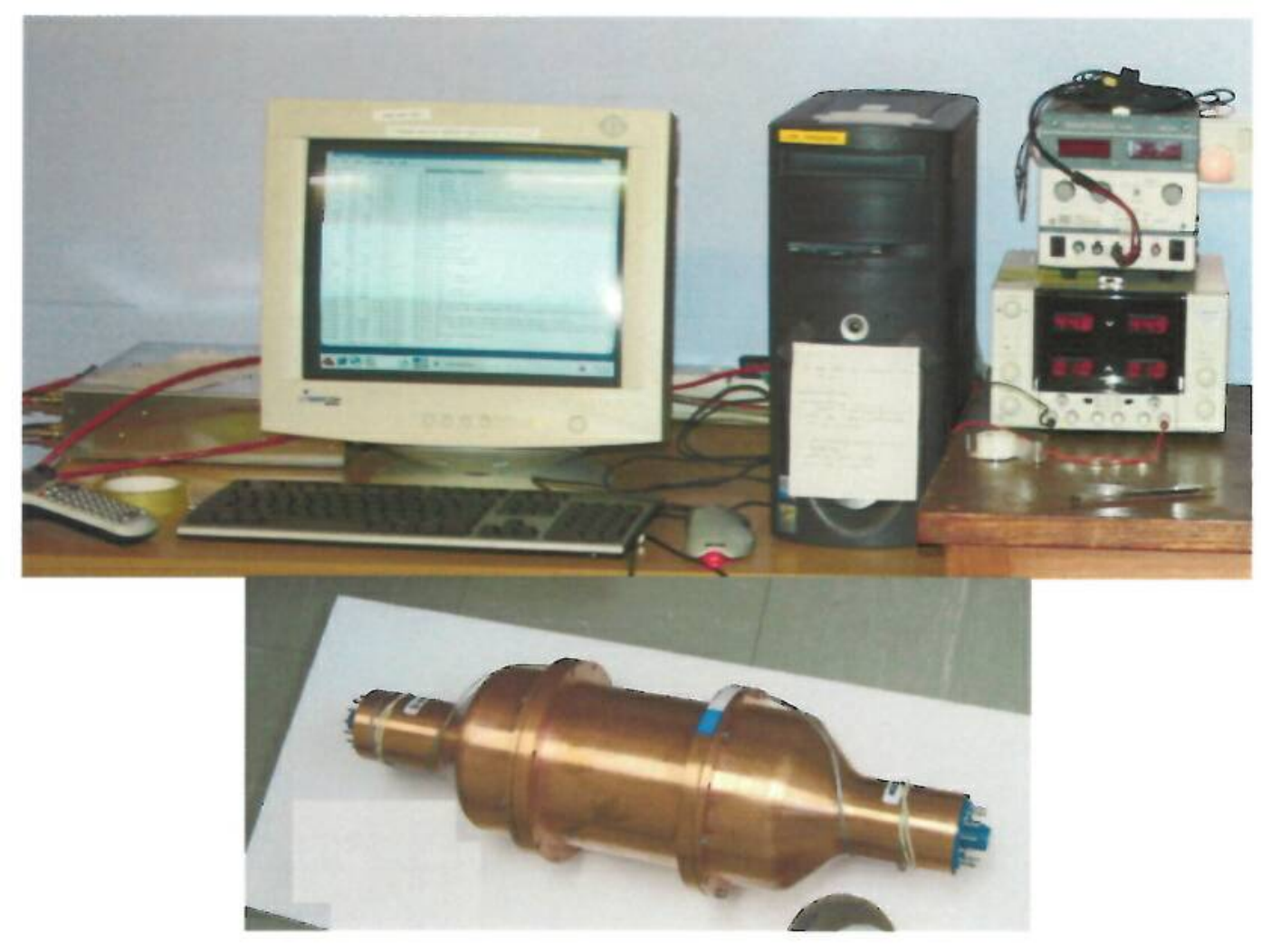




\section{TABLE OF CONTENTS}

INTRODUCTION

I. PERSONNel AND Institutions 5

II. EXPerimental Area, Beams and Schedule Considerations 6

III. RESPONSIBILITIES BY INSTITUTION - NON FERMILAB $\quad 8$

TV. RESPONSHBILITIES BY INSTYTUTION - FERMILAB 9

4.1 Fermilab ACCELERATOR Division 9

4.2 Fermilab Particle Physics Division 9

4.3 FERMILAB COMPUTING SECTION 9

4.4 FERMILAB ES\&H SECTION

$\begin{array}{ll}\text { V. SUMMARY OF COSTS } & 10\end{array}$

VI. SPECIAL CONSIDERATIONS

$\begin{array}{ll}\text { SIGNATURES } & 12\end{array}$

APPENDIXI-AREA LAYOUT

APPENDIX III - HAZARD IDENTIFICATION CHECKLIST 


\section{INTRODUCTION}

This is a memorandum of understanding between the Fermi National Accelerator Laboratory (Fermilab) and the experimenters of the NaI Crystal Test for DM-Ice from the University of Wisconsin who have committed to participate in detector tests to be carried out during the 2011 2012 Fermilab Neutrino program.

The memorandum is intended primarily for the purpose of recording expectations for budget estimates and work allocations for Fermilab, the funding agencies and the participating institutions. It reflects an arrangement that currently is satisfactory to the parties; however, it is recognized and anticipated that changing circumstances of the evolving research program will necessitate revisions. The parties agree to modify this memorandum to reflect such required adjustments. Actual contractual obligations will be set forth in separate documents.

\section{Description of Detector and Tests:}

The DM-Ice collaboration is designing a sodium-iodide (NaI) based detector for a direct dark matter search. The detectors should have low readout noise and background levels to carry out a sensitive search. A $17-\mathrm{kg}$ version of the experiment is running at the South Pole, $2500 \mathrm{~m}$ deep in the Antarctic ice, and a larger scale experiment is currently being designed. One of the keys to the success of the experiment is to have a good understanding of the background levels intrinsic in the $\mathrm{NaI}$ detectors.

To measure the background level, the detectors have to be shielded against cosmic rays. The lead shielding used for DAMIC (see T-987) in the Minos Underground Areas is a well-suited location for this test since it offers enough overburden to shield against cosmic rays, lead shielding, and experimental infrastructure.

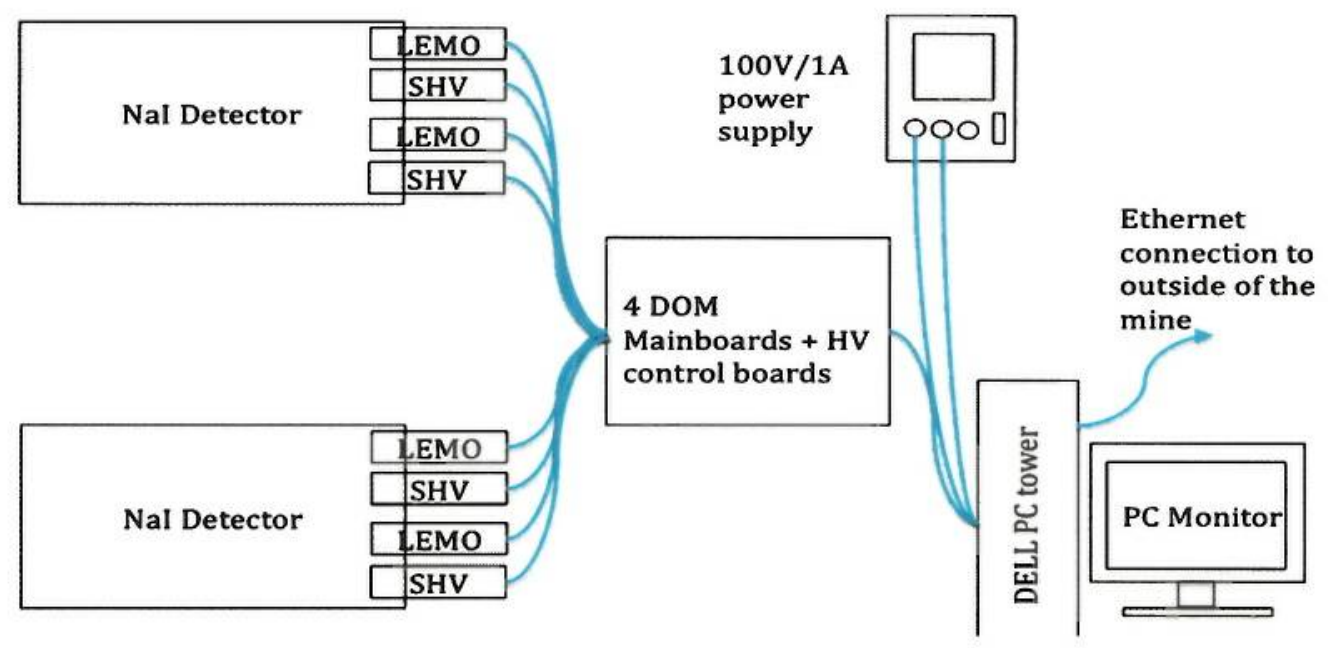

Figure 1.: A schematic of the data acquisition for the DM-Ice NaI test 


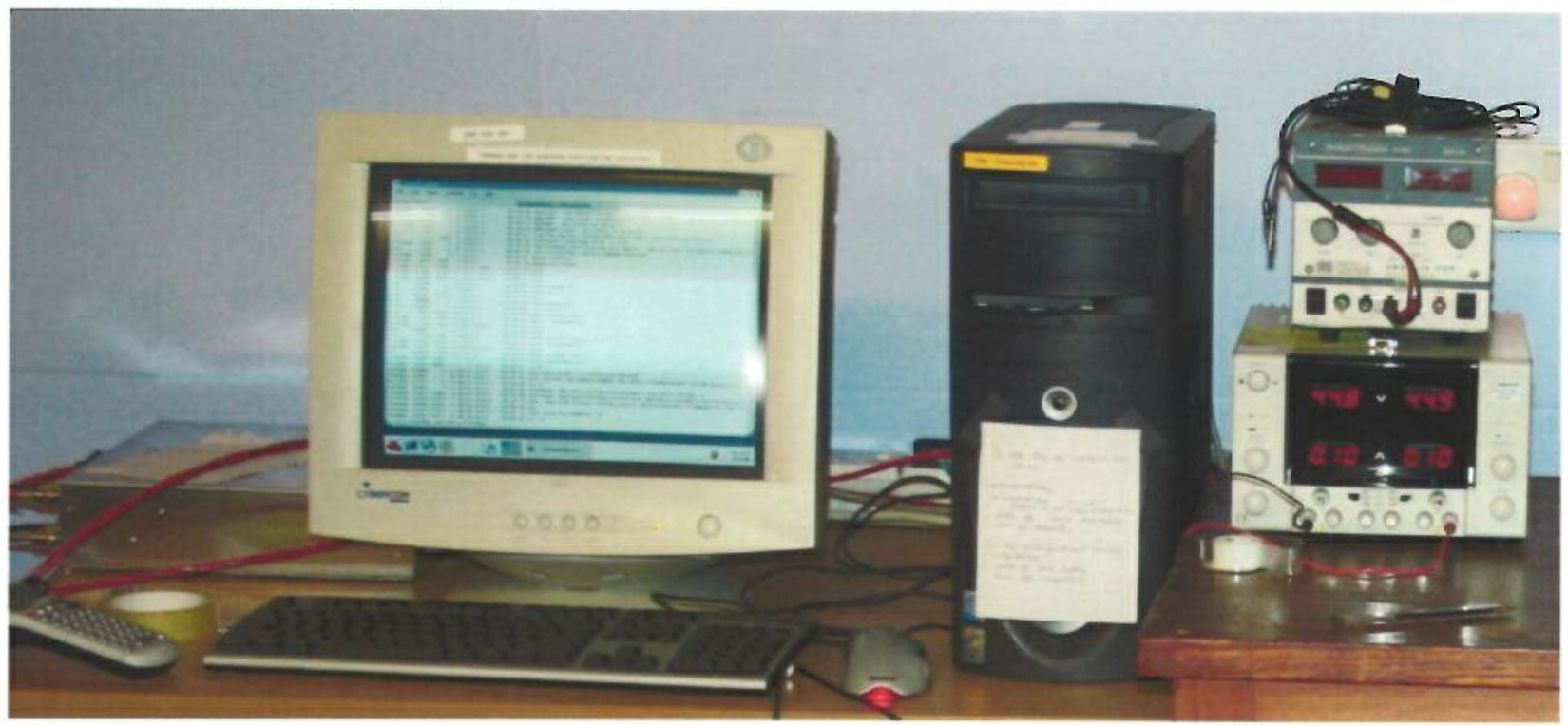

Figure 2: From left: electronics chassis containing the HV generator and pulse shape digitization board, a PC monitor and tower, and two power supplies. Only the bottom power supply will be used in this experiment.

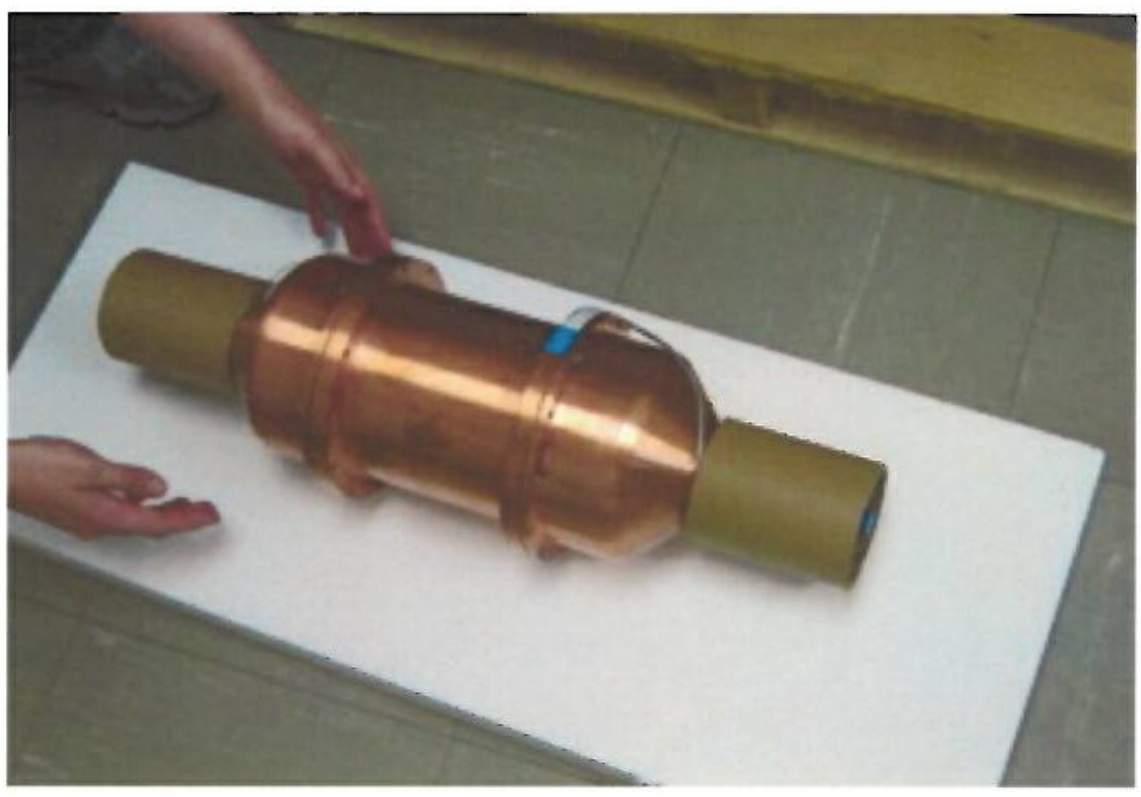

Figure 3: $\mathrm{NaI}(\mathrm{Tl})$ detector to be tested consisting of two PMTs placed on either ends. This detector along with PMT bases will be placed inside the lead shielding.

The goal of the test is to assess the background levels in the detector and to assess the characteristics of phosphorescence induced by muons and $100 \mathrm{keV}-3 \mathrm{MeV}$ gamma rays. 


\section{Personnel and Institutions:}

Spokesperson: Reina Maruyama

Physicist in charge of beam tests: Zachary Pierpoint

Fermilab liaison: Aria Soha

The group members at present are:

\begin{tabular}{|c|c|c|c|c|c|}
\hline & Institution & Collaborator & Country & $\underline{\text { Rank/Position }}$ & $\begin{array}{l}\text { Other } \\
\text { Commitments }\end{array}$ \\
\hline \multirow{7}{*}{1.1} & \multirow{7}{*}{$\begin{array}{l}\text { University of } \\
\text { Wisconsin, } \\
\text { Madison }\end{array}$} & Reina Maruyama & USA & Assistant Professor & IceCube, CUORE \\
\hline & & Karsten Heeger & USA & Associate Professor & Daya Bay, CUORE \\
\hline & & Zachary Pierpoint & USA & Graduate Student & \\
\hline & & Walter Pettus & USA & Graduate Student & \\
\hline & & Benjamin Broerman & USA & Undergraduate & \\
\hline & & Chris Hilgenberg & USA & Undergraduate & \\
\hline & & David Webber & USA & Postdoc & Daya Bay \\
\hline
\end{tabular}




\section{Experimental Area, Beams and Schedule Considerations:}

\subsection{LOCATION}

2.1.1 The apparatus for the beam test(s) will be located in the Minos Underground Area. The Detector Hall Access Tunnel has been recently used for the DAMIC experiment, and the experimenters request the use of their lead shielding for this test. Much of this area is well off the beam axis and would be ideal for the DM-Ice test. The experimental apparatus plus shielding will occupy a footprint roughly eight feet square. The apparatus requires standard $110 \mathrm{VAC}$ lines for the electronics.

\subsection{BEAM}

\subsubsection{BEAM TYPES AND INTENSITIES}

This test does not utilize any particle beams. The initial tests can be done when the beam is on, However the experiment should operate when the beam to the hall is off to minimize backgrounds.

\subsection{EXPERIMENTAL CONDITIONS}

\subsubsection{AREA INFRASTRUCTURE}

Location of the experiment, underground, is depicted in Appendix 1. Only the NaI(Tl) detector (see Fig. 3) and PMT voltage dividers will be placed inside the lead shielding. The electronics (Fig. 2) will be placed just outside. If possible, the PC tower shown should have Ethernet access to allow for remote operation and monitoring.

The NaI detector and data acquisition system are all light enough to be handled by a single person, though a cart to transport the equipment will be helpful.

Standard 110 VAC lines for the electronics are required, as well as one Ethernet connection. A second Ethernet connection is useful, though not absolutely necessary. The Ethernet connection to the data acquisition system will be used to remotely control and monitor the detector. It will also be used to transfer the data to servers at the University of Wisconsin.

The experiment acknowledges that due to the nature of the underground environment, ground water seeps from the ceiling and walls and pools on the floor, and will take measures to protect their equipment as they see fit, while abiding by fire hazard codes. 


\section{MOU for NaI Crystal Test for DM-Ice}

\subsubsection{EleCtronics NeEdS}

The experiment electronics are depicted in Figure 2, and consist of an electronics chassis containing the HV generator and pulse shape digitization board, a PC monitor and tower, and a small, commercial power supply. No rack, and therefore no rack protection equipment is necessary.

No PREP electronics are requested.

\subsubsection{Description OF TESTS}

After the initial setup and commissioning, the detector will be operated remotely via the Ethernet connection and data will be taken continuously, with an occasional interruption for detector calibration with gamma sources. The background levels at the detector and the system will be assessed, along with possible phosphorescence induced by muons and $100 \mathrm{keV}-3 \mathrm{MeV}$ gamma rays. The detector and data acquisition setup are shown in Figs. $1-3$.

\subsection{SCHEDULE}

The DM-Ice Nal crystal test is ready for immediate setup and installation. We expect it will take 2-3 days to setup and start the test. The experimenters expect to be able to start the tests upon approval, in January 2012. After the installation is complete the experimenters will collect data continuously for $\sim 1$ month with occasional short calibrations. During data taking the experimenters will look at the results and decide on the next steps for this project.

The experimenters acknowledge that the apparatus will have to be removed by March 1, 2012 for the duration of the 2012-2013 Fermilab shutdown, and the underground space after the shutdown will need to be renegotiated. 


\section{RESPONSIBILITIES BY INSTITUTION - NON FERMLLAB}

\subsection{UNIVERSITY OF WISCONSIN:}

- The University of Wisconsin will be responsible for supplying the detector and data acquisition electronics as well as the personnel to run the detector. The equipment supplied are:

- Nal(T1) detector, each equipped with two photomultiplier tubes and bases. (qty: 2)

- 2 electronics chassis containing 2 DOM mainboards and HV control boards. (2 BNC output, 2 SHV output, 1 input from PC) (qty 2)

- 4 BNC - LEMO adaptors

- 1 Tower PC equipped with one IceCube "dor" data acquisition card

- PC monitor, keyboard, and mouse

- 1 power supply (120V/1A)

- 4 SHV cables

- 4 LEMO or BNC cables

- Connector/cable between power supply and dor card

- Connector/cable between dor card and chassis to mainboards

- 1 Ethernet cable 


\section{rV, RESPONSIBILITIES BY INSTITUTION - FERMILAB}

\subsection{FERMILAB ACCELERATOR DiVISTON:}

No accelerator division support is required.

\subsection{FERMILAB PARTICLE PHYSICS DIVISION:}

4.2.1 The test-beam efforts in this MOU will make use of the MrNos Underground Areas as outlined in Section II. The Fermilab Particle Physics Division will be responsibie for coordinating overall activities in the MiNos Underground Area. [2 person-weeks]

4.2.2 Technical support to assist in moving the experimental equipment into and out of the Minos Underground Area and moving the lead shielding [0.4 person-weeks]

4.2.3 A person appropriately trained to handle sealed-sources for occasional detector calibration. [0.8 person-weeks]

4.2.4 Conduct a NEPA review of the experiment.

4.2.5 Provide day-to-day ES\&H support/oversight/review of work and documents as necessary.

4.2.6 Provide safety training as necessary, with assistance from the ES\&H Section.

4.2.7 Update/create ITNA's for users on the experiment.

4.2.8 Coordinate the ES\&H Operational Readiness Clearence Review or other required safety reviews. [0.2 person-weeks]

\subsection{FERMILAB COMPUTING SECTION}

4.3.1 Internet access underground/on surface to allow for remote operation and monitoring.

\subsection{FERMILAB ES\&H SECTION}

\subsubsection{Assistance with safety reviews.}

4.4.2 Loan of radioactive sources, $\mathrm{Co}-57, \mathrm{Co}-60$, and $\mathrm{Cs}-137$ for 1 hour calibration runs scattered throughout the duration of the experiment.

4.4.3 Provide safety training, with assistance from PPD, as necessary for experimenters. 


\section{MOU for NaI Crystal Test for DM-Ice}

\%. SuMMARY OF COSTS

\begin{tabular}{|c|c|c|}
\hline Source of Funds [\$K] & Materials \& Services & $\begin{array}{c}\text { Labor } \\
\text { (person-weeks) }\end{array}$ \\
\hline Particle Physics Division & 0.0 & 3.4 \\
\hline Accelerator Division & 0 & 0 \\
\hline Computing Section & 0 & 0 \\
\hline ES\&H Section & 0 & 0 \\
\hline & & \\
\hline Totals Fermilab & $\$ 0.0 \mathrm{~K}$ & 3.4 \\
\hline Totals Non-Fermilab & $\$ 15 \mathrm{k}$ & 4 \\
\hline
\end{tabular}




\section{General Considerations}

6.1 The responsibilities of the Spokesperson and the procedures to be followed by experimenters are found in the Fermilab publication "Procedures for Researchers":

(http://www.fnal.gov/directorate/PFX/PFX.pdf). The Spokesperson agrees to those responsibilities and to ensure that the experimenters all follow the described procedures.

6.2 To carry out the experiment a number of Environmental, Safety and Health (ES\&H) reviews are necessary. This includes creating an Operational Readiness Clearance document in conjunction with the standing Particle Physics Division committee. The Spokesperson will follow those procedures in a timely manner, as well as any other requirements put forth by the Division's Safety Officer.

6.3 The Spokesperson will ensure one person is on-call and available by phone at all times whenever the detector is being operated and that this person is knowledgeable about the experiment's hazards.

6.4 All regulations concerning radioactive sources will be followed. No radioactive sources will be carried onto the site or moved without the approval of the Fermilab ES\&H section.

6.5 All items in the Fermilab Policy on Computing will be followed by the experimenters. (http:/computing. fnal.gov/cd/policy/cpolicy.pdf).

6.6 The Spokesperson will undertake to ensure that no PREP or computing equipment be transferred from the experiment to another use except with the approval of and through the mechanism provided by the Computing Section management. The Spokesperson also undertakes to ensure no modifications of PREP equipment take place without the knowledge and written consent of the Computing Section management.

6.7 The experimenters will be responsible for maintaining both the electronics and the computing hardware supplied by them for the experiment. Fermilab will be responsible for repair and maintenance of the Fermilab-supplied electronics. Any items for which the experiment requests that Fermilab performs maintenance and repair should appear explicitly in this agreement.

At the completion of the experiment:

6.8 The Spokesperson is responsible for the return of all PREP equipment, computing equipment and non-PREP data acquisition electronics. If the return is not completed after a period of one year after the end of running the Spokesperson will be required to furnish, in writing, an explanation for any non-return.

6.9 The experimenters agree to remove their experimental equipment as the Laboratory requests them to. They agree to remove it expeditiously and in compliance with all ES\&H requirements, including those related to transportation. All the expenses and personnel for the removal will be borne by the experimenters unless removal requires facilities and personnel not able to be supplied by them, such a rigging, crane operation, etc.

6.10 The experimenters will assist Fermilab with the disposition of any articles left in the offices they occupied.

6.11 An experimenter will be available to report on the test beam effort at a Fermilab All Experimenters' Meeting. 


\section{SignATURES:}

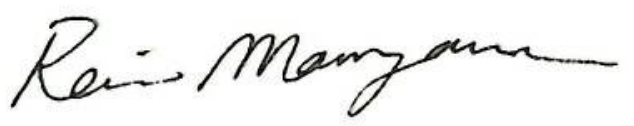

$11 / 09 / 2011$

Reina Maruyama, Experiment Spokesperson

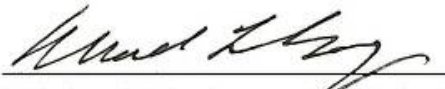

// /10/2011

Michael Lindgren, Particle Physics Division, Fermilab

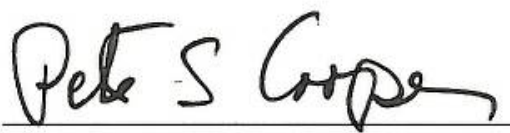

N/2//2011

Peter Cooper, Computing Section, Fermilab

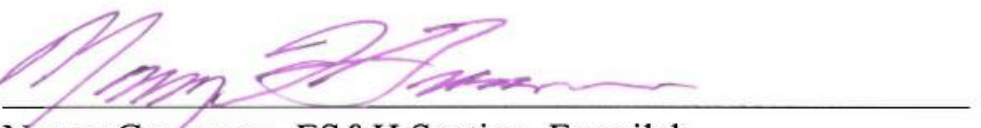

1) / / / 2011

Nancy Grossman, ES\&H Section, Fermilab

$\frac{2}{\text { Greg Bock, Associate Director for Research, Fermilab }}$

$/ / / 2 / / 2011$

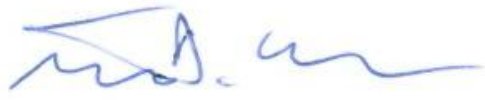

Stuart Henderson, Associate Director for Accelerators, Fermilab 


\section{MOU for NaI Crystal Test for DM-Ice}

\section{APPENDiX I: AREA LAYOUT}

The test will utilize the lead shielding used for the DAMIC experiment. A table next to the shielding for the power supply, data acquisition electronics, and computer is requested.

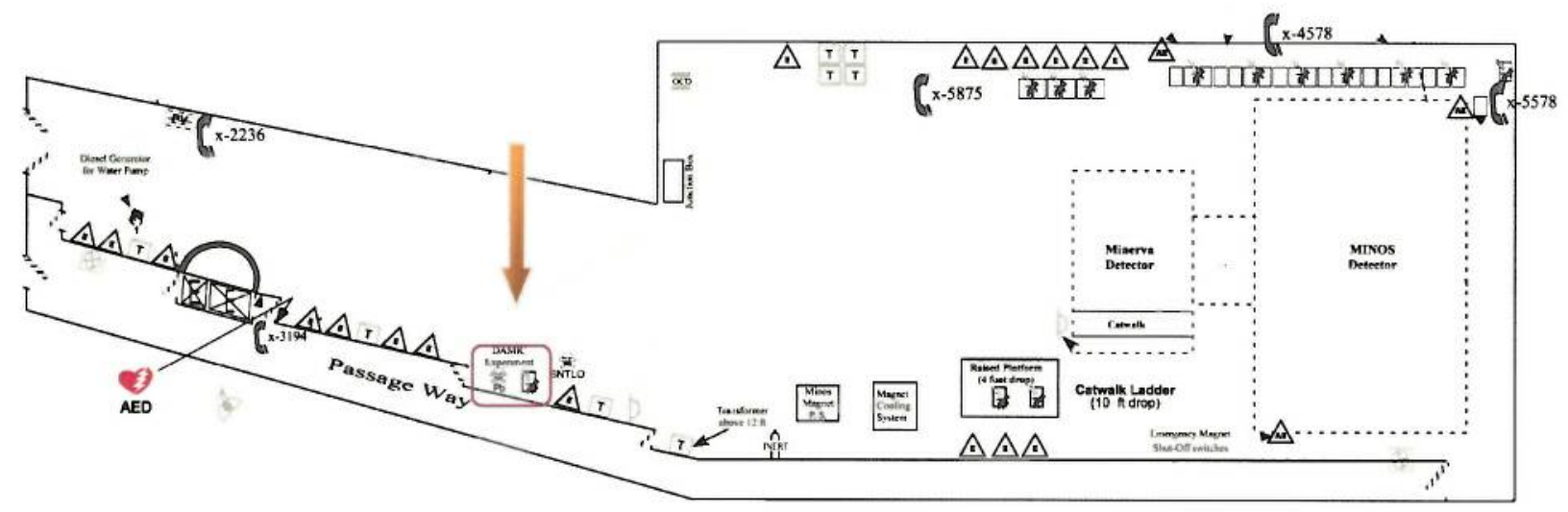




\section{APPENDIX III: - HAZARD IDENTIFICATION CHECKLIST}

Items for which there is anticipated need have been checked. See next page for detailed descriptions of categories.

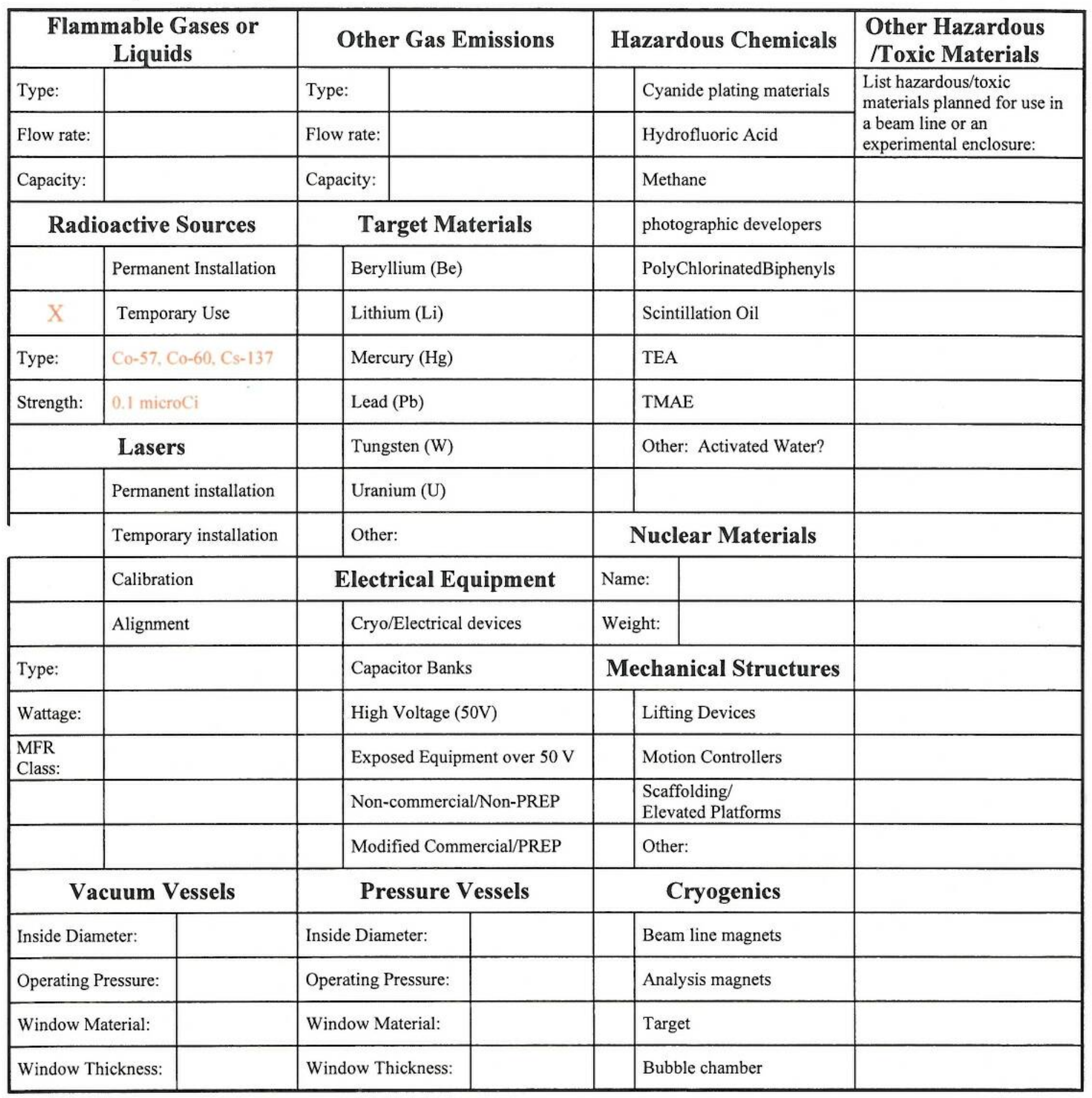




\title{
Other Gas EMission
}

Greenhouse Gasses (Need to be tracked and reported to DOE)

\author{
- Carbon Dioxide, including $\mathrm{CO}_{2}$ mixes such as $\mathrm{Ar} / \mathrm{CO}_{2}$ \\ D Methane \\ $\square \quad$ Nitrous Oxide \\ $\square$ Sulfur Hexaftuoride \\ Hydro fluorocarbons \\ - Per fluorocarbons \\ 口 Nitogen Trifluoride
}

\section{NUClEar Materials}

\section{Reportable Elements and Isotopes / Weight Units / Rounding}

\begin{tabular}{|c|c|c|c|c|c|}
\hline Name of Material & Code & $\begin{array}{l}\text { Reporting Weight } \\
\text { Unit Report to } \\
\text { Nearest Whole Unit }\end{array}$ & $\begin{array}{l}\text { Element } \\
\text { Weight }\end{array}$ & $\begin{array}{l}\text { Isotope } \\
\text { Weight }\end{array}$ & $\begin{array}{c}\text { Isotope } \\
\text { Weight } \%\end{array}$ \\
\hline Depleted Uranium & 10 & Whole Kg & Total U & $\mathrm{U}-235$ & $\mathrm{U}-235$ \\
\hline Enriched Uranium & 20 & Whole Gm & Total U & $\mathrm{U}-235$ & $\mathrm{U}-235$ \\
\hline Plutonium-242 ${ }^{1}$ & 40 & Whole Gm & Total Pu & $\mathrm{Pu}-242$ & $\mathrm{Pu}-242$ \\
\hline Americium- $241^{2}$ & 44 & Whole Gm & Total Am & $\mathrm{Am}-241$ & - \\
\hline Americium- $243^{2}$ & 45 & Whole Gm & Total Am & $\mathrm{Am}-243$ & - \\
\hline Clirium & 46 & Whole $\mathrm{Gm}$ & Total Cm & $\mathrm{Cm}-246$ & - \\
\hline Califomium & 48 & Whole Microgram & - & $\mathrm{Cf}-252$ & - \\
\hline Pfutoniurn & 50 & Whole Gm & Total $\mathrm{Pu}$ & $\mathrm{Pl}-239+P_{\mathrm{u}-241}$ & Pu-240 \\
\hline Enriched Lithium & 60 & Whole Kg & Total Li & $\mathrm{Li}-6$ & $\mathrm{Li}-6$ \\
\hline Uranium-233 & 70 & Whole Gm & Total U & $\mathrm{U}-233$ & $\mathrm{U}-232(\mathrm{ppm})$ \\
\hline Normal Uraniwan & 81 & Whole $\mathrm{Kg}$ & Total U & - & - \\
\hline Neptunitant-237 & 82 & Whole Gm & Total $\mathrm{Np}$ & - & - \\
\hline Plutonium-238 & 83 & Gm to tenth & Total Pu & Pu-238 & $\mathrm{Pu}-238$ \\
\hline Deuterium ${ }^{4}$ & 86 & Kg to tenth & $\mathrm{D}_{2} \mathrm{O}$ & $\mathrm{D}_{2}$ & \\
\hline Trittum ${ }^{3}$ & 87 & Gm to hundredth & Total H-3 & - & - \\
\hline Thorium & 88 & Whole Kg & Total Th & - & - \\
\hline Uranium in Cascades $^{6}$ & 89 & Whole Gm & Total U & $\mathrm{U}-235$ & U.235 \\
\hline
\end{tabular}

${ }^{1}$ Report as $\mathrm{Pu}-242$ if the contained $\mathrm{Pu}-242$ is 20 percent or greater of total plutonum by weight; otherwise, report as Pu 239.241.

${ }^{2}$ Americium and Neptunium-237 contained in plutonium as part of the natural in-growth process are not required to be accounted for or reported until separated from the plutonium.

${ }^{3}$ Report as Pu-238 if the contained Pu-238 is 10 percent or greater of total plutonium by weight; ofherwise, report as plutoniam Pu 239-241.

${ }^{4}$ For deuterium in the form of heavy water, both the element and isotope weight fields should be used; otherwise, report isotope weight only.

5 Tritium contained in water (H2O or D2O) used as a moderator in a nuclear reactor is not an accountable material.

${ }^{6}$ Uranium in cascades is treated as enriched uranium and should be reported as material type 89. 